\title{
The Impact of Video Service Regulation on the Construction of Broadband Networks to Low- Income Households
}

Abstract: This paper demonstrates that policies hindering a new entrant's ability to sell video programming, such as forcing entrants to obtain a local cable franchise agreement, will strongly diminish that entrant's incentive to deploy fiber to low-income households. Using publicly-available data from the U.S. Census Bureau, we employ a simple graphical analysis and a simulation of network deployment to consider the impact that video service regulation would have on broadband network deployment. We show that a new broadband entrant will serve substantially more low-income households than it would if regulation sharply curtails or delays video deployment. In our simulation, video service takes on the role of a "silver bullet" - i.e., when the network firm can bundle video services, the percentage of poverty and minority homes with access to the network rises significantly. Accordingly, our analysis indicates that policies that make video competition more difficult will lead to significantly lower deployment of advanced broadband networks in low-income areas than would occur with pro-entry video policies.

Authors: George S. Ford is Chief Economist, Phoenix Center for Advanced Legal \& Economic Public Policy Studies. His education includes: Ph.D, Economics, Auburn University, 1994; and a B.S., Economics, Auburn University, 1990. Thomas M. Koutsky is Resident Scholar, Phoenix Center for Advanced Legal \& Economic Public Policy Studies. His education includes: J.D., University of Chicago Law School, 1991; and B.A., Political Science, University of Illinois at Urbana-Champaign, 1988. Lawrence J. Spiwak is President, Phoenix Center for Advanced Legal \& Economic Public Policy Studies. His education includes: J.D., Cardozo School of Law, 1989; and a B.A., Middle Eastern Studies, George Washington University, 1986. The views expressed in this paper are the authors' alone and do not represent the views of the Phoenix Center for Advanced Legal and Economic Public Policy Studies, its Adjunct Fellows, or any of its individual Editorial Advisory Board members. We are indebted to T. Randolph Beard, Professor of Economics, Auburn University, and Adjunct Fellow with the Phoenix Center, for his assistance on prior versions of the paper. 


\section{INTRODUCTION}

Modern communications policy in the United States is focused on fostering and encouraging the widespread deployment of advanced communications networks to all American households. President George W. Bush has established a goal of "universal, affordable access for broadband technology by the year 2007," and influential policymakers, both Republican and Democrat, almost universally share the aspiration that no community or group of citizens should be without robust broadband network alternatives. ${ }^{2}$

While policymakers have zealously focused on the availability of "broadband" functionality (e.g., faster Web surfing capability) to households, many have failed to realize that fiber will not be widely deployed solely to provide Internet access. In fact, revenue streams from other types of communications services are critical for the construction of advanced broadband networks. This paper explains how policies which ensure entrants can readily provide video programming services along with voice and data services, will contribute substantially to the widespread deployment of advanced communications networks, particularly in low-income neighborhoods. In so doing, our findings provide empirical support for the assertion by Federal Communications Commission ("FCC") Chairman Kevin J. Martin that additional multichannel video competition would also "stimulate broadband deployment."3

Ever since the Internet and the World Wide Web became a significant business and mass-market phenomenon, there has been a strong concern that a "digital divide" will emerge between rich and poor, or urban and rural, consigning the digital "have-nots" to a

\footnotetext{
${ }^{1}$ The White House, A New Generation of American Innovation, special White House report, April 2004, 11, http://www.whitehouse.gov/infocus/technology/economic policy200404/innovation.pdf. Current FCC Chairman Kevin J. Martin has made achieving this goal one of his 'core priorities.' Statement of Chairman Kevin J. Martin, "In the Matter of Petition of SBC Communications Inc. for Forbearance from the Application of Title II Common Carrier Regulation to IP Platform Services," WC Docket No. 04-29 (May 5, 2005).

${ }^{2}$ Concern over a "digital divide" appears to be bipartisan. A recent report by the Congressional Research Service lists more than a dozen legislative proposals, introduced by Republicans and Democrats alike, that share the goal of promoting more broadband deployment, particularly in disadvantaged areas. Congressional Research Service, "Broadband Internet Access: Background and Issues," IB10049 (June 9, 2005).

${ }^{3}$ Leslie Cauley, "FCC Chief Considers Forcing Cable TV Competition," USA Today, August $22,2005$.
} 
backward, pre-Information Age subsistence. ${ }^{4}$ Similar concerns about whether certain neighborhoods or groups would be left behind resulted in "build-out" and "anti-redlining" rules that became conditions of granting monopoly cable franchises. ${ }^{5}$ But when applied to new entrants, these altruistic requirements can be self-defeating and often erect insurmountable barriers to entry for new firms. ${ }^{6}$ Build-out and anti-redlining requirements are not imposed on new entrants in any other sector of the telecommunications industry and are certainly not the general rule in the U.S. economy. For example, a firm that wants to compete with Wal-Mart is not required to build a store in every town where a Wal-Mart exists.

Instead of extending anti-redlining and build-out requirements to new entrants, public policy can combat the threat of a "digital divide" and ensure more widespread deployment of advanced communications networks by allowing entrants the freedom to bundle video with a broadband offering. Adding video to the product mix increases the

\footnotetext{
${ }^{4}$ For two examples of this viewpoint, see U.S. Department of Commerce, National Telecommunications and Information Administration, Falling Through the Net: Defining the Digital Divide, 1999 (describing problems of a rich-poor "digital divide"); see also U.S. Department of Commerce, National Telecommunications and Information Administration, $A$ Nation Online: Entering the Broadband Age, 2004 (expressing concern over potential ruralurban divide for broadband services) (hereinafter NTIA NATION ONLINE REPORT).

${ }^{5}$ Cable franchises are typically granted by municipal or county authorities under the pretext that cable firms use public rights-of-way and should pay for their use. Prior to the 1992 Cable Act, there was no prohibition against exclusive franchises. However, despite the de jure prohibition against cable franchises (see, e.g., General Franchise Requirements, U.S. Code 47 (2000), $\$ 541(a)(1))$, as discussed passim, build-out and other entry deterring requirements nonetheless left a world of de facto exclusivity. For an interesting analysis of franchising in cable television, see Oliver E. Williamson, "Franchise Bidding for Natural Monopolies in General and with Respect to CATV," Bell Journal of Economics 7 (1976): 73-104.
}

${ }^{6}$ See, e.g., George S. Ford, Thomas M. Koutsky and Lawrence J. Spiwak, "The Economics of Build-Out Rules in Cable Television," Hastings Communications and Entertainment L. J. 28 (2006): 207 (showing that ex ante "build-out" rules, when imposed on new entrants, deter entry significantly and force new entrants to bypass communities entirely) and citations therein. Indeed, the FCC recognized over ten years ago that the local cable franchising process is "the most important policy relevant barrier to competitive entry in local cable markets." Federal Communication Commission, "In re Implementation of Section 19 of the Cable Television Consumer Protection and Competition Act of 1992, Annual Assessment of the Status of Competition in the Market for Delivery of Video Programming," FCC Rcd 9 (1994): 7442, app. H, 375ff.; see also Richard Posner, "The Appropriate Scope of Regulation in the Cable Television Industry," Bell Journal of Economics 3 (1972): 98-129. Empirical evidence of the negative effects of build-out requirements is provided in Thomas W. Hazlett and George S. Ford, "The Fallacy of Regulatory Symmetry: An Economic Analysis of the 'Level Playing Field' in Cable TV Franchising Statutes," Business \& Politics 3 (2001): 21-46. 
revenue potential of the network, thereby increasing entry. Expanding the product mix to include video also substantially reduces the payback period on the network investment. A shorter payback period makes network investment less risky, so the firm will incur a lower cost of capital (e.g., it can borrow at lower interest rates) and can invest in more network building. Since low-income households subscribe to video service at roughly the same rate as higher income households, ${ }^{7}$ the ability of entrants to offer video services substantially improves the financial case for fiber deployment in low-income neighborhoods. That is, while broadband service subscription is highly sensitive to income, video subscription is not. Building modern broadband infrastructure in low-income areas, consequently, becomes relatively more attractive when the broadband provider can also provide video services.

In this paper, we examine the network deployment decision for new entrants by simulating how many households a new entrant would build its network to ("households passed," in industry terms) and how that network construction decision would be impacted by the type of services the new entrant is able to sell over that network. We simulate the network deployment decision in the State of Texas and this simulation shows that a new entrant will pass substantially more lowincome households if that entrant can readily offer video with voice and broadband Internet access services. If the new entrant's ability to sell video services is sharply curtailed or delayed, it will pass fewer low-income households with its network. ${ }^{8}$ In our simulation, video

\footnotetext{
${ }^{7}$ See, e.g., Robert Kieschnick and B. D. McCullough, "Why Do People Not Subscribe to Cable Television: A Review of the Evidence" (paper presented at the Telecommunications Policy Research Conference, Virginia, October 4, 1998), http://www.tprc.org/abstracts98/kieschnick.pdf.
}

${ }^{8}$ Given ample evidence of various entry-deterring policies extracted at the franchise level by local officials, Texas recently passed a law that abolishes local franchise requirements in favor of a single, state-wide franchise administered by the Public Utility Commission. Texas Legislature, Act Relating to Furthering Competition in the Communications Industry (September 7, 2005), S.B. 5, 79th Leg., 2d Sess., enrolled version (Texas 2005). In so doing, not only does this law end the ability for local politicians to extract entry deterring concessions, but also considerably speeds up the entry process for new video competitors like Texas local telephone companies AT\&T or Verizon, who otherwise might have had to obtain hundreds of local video franchises in order to sell cable video services to their existing telephone customers in the state. Critics of the Texas law contend that the legislation will "damage .. communities," see Complaint, Texas Cable \& Telecommunications Ass'n $v$. Perry, Case No. 05-CV-721-LY, U.S. District Court, Western District of Texas, filed September 8, 2005, 23ff., and "divid[e] communities into the 'haves' and the 'have nots' of advanced technologies." Texas Cable \& Telecommunications Association, "TCTA Sues State of Texas over New Telecom Law," news release, September 8, 2005, http:/www.txcable.com/ 
service takes on the role of a "silver bullet" - i.e., when the network firm can bundle video, the percentage of poverty and minority homes with access to the network rises substantially. Because we use a number of assumptions, our simulation results should not be used to assert that a certain level of penetration is achievable within any particular time period. Our simulation is also based on a fiber-to-thehome ("FTTH") network, which is not being deployed in all markets across the country. Our simulation certainly indicates that policies that make video competition more difficult will lead to significantly lower deployment of advanced communications networks in low-income areas than pro-entry video policies. These findings should not be significantly implicated by any of the simplifications or limitations of the simulation analysis. ${ }^{9}$

This paper is outlined as follows. In Section II, we present a simple conceptual analysis showing the role bundling can have in driving network deployment, particularly to low-income households. In Section III, we present a computer simulation of network deployment. This simulation will serve to illustrate and quantify the importance to network deployment of having the ability to sell multichannel video in a "triple-play" bundle. Concluding comments are in the final section.

\section{INCOME AND ACCESS: A CONCEPTUAL DISCUSSION}

The U.S. telecommunications industry is entering an era in which policymakers have chosen to rely on so-called "inter-modal" competition between facilities-based, broadband networks that can support a number of different services - most notably, video, voice,

News/PressReleases/PressRelease20050908.asp. In our research, we find no evidence, theoretical or empirical, to support this claim. The opposite, in fact, is true - removing the franchise barrier to entry will lead to more network deployment, particularly to low-income households.

\footnotetext{
${ }^{9}$ Franchising, through both inherent bureaucratic delay and the extraction of political concessions, is not the only barrier to entry in video markets. Other potential hindrances to entry include the lax regulatory oversight over access to video programming, particularly programming with vertical relationships with incumbent cable operators. See James W. Olson and Lawrence J. Spiwak, "Can Short-Term Limits on Strategic Vertical Restraints Improve Long-Term Cable Industry Market Performance?," Cardozo Arts \& Ent. L.J. 13 (1995): 283, http://www.phoenix-center.org/library/prog_access.doc. Policymakers should not only focus on removing legal barriers to entry like franchising, but they should also focus on breaking down economic and operational barriers to entry, such as access to programming.
} 
and broadband Internet access. ${ }^{10}$ Two theoretical observations from that development are highly relevant to the present analysis. First, markets with greater potential revenues can support more facilitiesbased entry. ${ }^{11}$ Since multichannel video is a highly-valued and widely-consumed service, public policies that impede the sale of video services by prospective entrants over new, multi-service networks will unambiguously reduce entry. Second, entry is facilitated when new technology permits owners to convert what traditionally were "singleuse" networks into "multi-use" networks and leverage their assets to "spill over" into related markets. This is because such spillovers reduce entry costs. ${ }^{12}$ The combination of larger markets and spillovers can produce substantially more entry. ${ }^{13}$ For the same reasons, public policy that denies access to particular markets or limits the potential revenues in serving a market will curtail network construction.

To illustrate further, we start our analysis with a simple proposition: in a market economy, a firm will construct an advanced, multi-service broadband network to a household (or group of households) if the expected net revenues from the household (or group of households) exceed the costs of deploying and providing access to that network. Symbolically, if a household is expected to generate $r$ in net revenues and the up-front cost of access to the network is $k$, then access will be provided when $r \geq k$. ${ }^{14}$ Access is more widely available

${ }^{10}$ George S. Ford, Thomas M. Koutsky and Lawrence J. Spiwak, "Competition after Unbundling: Entry, Industry Structure and Convergence," Federal Communications L.J. 59 (forthcoming Winter 2007).

${ }^{11}$ More precisely, when we refer to revenue streams, we are talking about contributions to net income, by which we mean incremental cash receipts exceeding incremental cash expenditures.

${ }^{12}$ See generally Ford, Koutsky and Spiwak, "Competition after Unbundling," supra note 10 (discussing spillover effects on entry).

${ }^{13}$ Bundling also reduces risk, promoting entry in at least two other ways. Adding service offerings to the network increases the chance that customers will purchase at least one service from a network that passes their homes, so there is less downside risk to building the network. Moreover, by offering multiple services, the provider faces less risk of being unable to recover its investment should customers cease to be interested in a particular service (as has happened with stand-alone long distance service, for example). Id.

\footnotetext{
${ }^{14}$ Note that $r$ is the present value of revenues over the investment horizon and are net of marginal costs. All capital investments $k$ are up-front, one-time expenditures. In this analysis, we treat network construction as a one-time occurrence. In reality, network costs are incurred over time as networks are maintained and expanded. Further, there exists a variety of factors that influence the profitability of network construction including features of the tax code, government subsidies, and other factors. The simplifying assumptions have no effect on the
} 
as $r$ becomes larger relative to $k$ (that is, $r$ rises while $k$ is constant, or $k$ falls while $r$ is constant).

For many goods and services in the economy, and especially for broadband Internet access, consumption rises with income (y). For our purposes, we denote this relationship as $r(y)$ - in other words, the revenue a network owner can expect to receive from a household (or group of households) is a function of that household's income (in this case, a positive function of income). ${ }^{15}$ A household (or group of households) will be offered service only if $r(y) \geq k$. This condition is more easily satisfied when $k$ is constant as income $(y)$ increases.

Policymakers worried about a "digital divide" are, in essence, postulating their concern that $r(y)$ at low incomes will consistently fall below $k$, so that a profit-maximizing firm will not provide service in low-income areas. We illustrate the situation in Figure 1. In the figure, dollars are on the vertical axis and income is on the horizontal axis. As indicated in the NTIA NATION ONLINE REPORT, ${ }^{16}$ revenues for broadband Internet access services rise with income, as shown by the line labeled $r(y)$. For some capital cost $k$ (which is unrelated to income here), customers living in geographic areas with average incomes less than $y^{*}$ will not be offered service (whether their home is "passed" by the new network), while those consumers living in areas with average incomes larger than $y^{*}$ will be offered service (their homes will be "passed" by the new fiber network). Note that the seller is not required to be driven by any ill motive to avoid low-income areas - it is simply engaging in profit-maximizing behavior encouraged by a capitalist economy. ${ }^{17}$ Nevertheless, policymakers may be legitimately concerned about whether households with

general implications of our theoretical analysis. Since we employ sophisticated cost models in our simulation, many of these complexities are incorporated into the modeling effort.

\footnotetext{
${ }^{15}$ We do not mean to imply that income is the only factor that impacts a household's spending on communications services. As shown in the NTIA NATION ONLINE REPORT, supra note 4, there are several other factors, specifically family size and age of children. We, however, focus on household income because many policymakers are particularly concerned with that demographic.
}

\section{${ }^{16}$ NTIA NATION ONLINE REPORT, supra note 4.}

${ }^{17}$ We do not adopt the term "redlining" here. "Redlining" is typically associated with geographic discrimination. In our model, there is no discrimination per se, since the firm provides service as long as $r(y)>k$ regardless of race, religion, or any other factor.

"Redlining" is a more meaningful concept in mortgage markets, where the lender may base decisions not on a customer's actual financial status, but rather on the customer's financial status in a particular geographic location (say, a financially successful individual living in a low-income neighborhood). 
incomes less than $y^{*}$ will have access to broadband services for social and economic reasons that cannot be captured as profits by the seller.

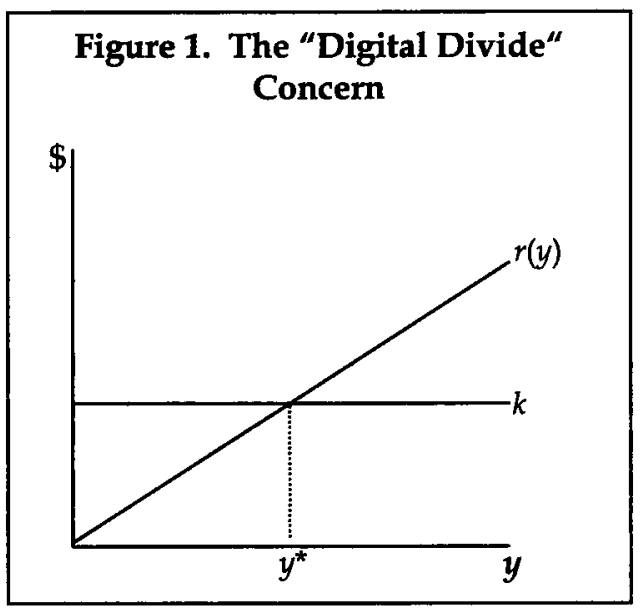

The single-service analysis in Figure 1 is too simple for modern communications networks. Firms today can build robust, multiservice fiber networks that provide not only broadband Internet access service but also video and voice services. The ability of these networks to support services in addition to high-speed Internet access influences the deployment of these networks and, as a result, the availability of high-speed Internet access. Notably, the availability of multiple services increases the potential revenues that a network owner can receive from every household, even the poorest of households. The simple ability to sell multiple products on a network will decrease the potential for a "digital divide."

Figure 2 demonstrates the impact of bundling on network deployment. Assume that $k$ is the cost of providing broadband service; if the firm provides video services, then capital costs increase by $d$. As a result, the total capital cost per household to the firm for providing the bundle is $k+d$. If we assume that the consumption of broadband (Good 1) and video (Good 2) have identical average expenditures and income relationships $\left(r_{1}=r_{2}\right)$, then revenues for the "double play"

\footnotetext{
${ }^{18}$ Our simulation below shows that a crucial component of this bundle is the availability of multichannel video services. These services generate a lot of revenue for network providers. As a result, the $r(y)$ for every household, rich or poor, will be larger if multichannel video is part of the "bundle."
} 
bundle will be $r_{12}=2 r_{1}=2 r_{2}$. In Figure 2 , we add to Figure 1 the revenue line for the bundle of broadband and video $\left(r_{12}\right) .{ }^{19}$

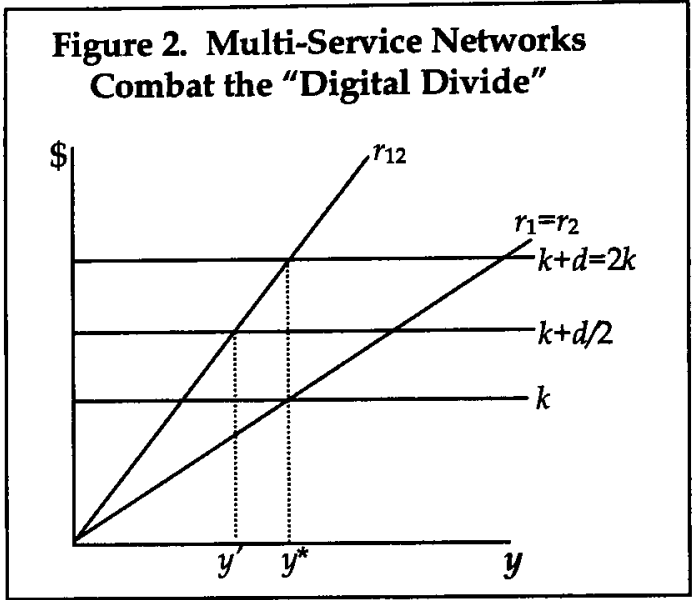

In Figure 2, if $d=k$, then we have the line labeled $k+d=2 k$, and the equilibrium income level for service will again be $y^{*}$ (as in Figure 1). If $d<k$ (that is, if there is a "spillover" effect, which we often observe in multi-service fiber-rich networks), then the intersection of $k+d$ and $r_{12}$ will lie to the left of $y^{*}$. For example, if the cost of deploying the second service is one-half the cost of deploying the first service, as with line $k+d / 2$, then the average household income level at which service will be provided falls from $y^{*}$ to $y^{\prime}$. Figure 2 shows that as long as some "spillover" effect reduces the investment needed for the second service compared with providing it on a stand-alone basis (that is, $d<k$ ), a firm will build out to more lower-income households if it can sell a bundle than if it were limited to offering only one of the two products. The ability to bundle Goods 1 and 2 increases the potential market size, which shrinks the presence of a "digital divide."

Figure 2 shows that because of supply-side "spillover" effects, bundling multiple services will result in a larger, more extensive network - in industry terms, the network will "pass" more lower-

\footnotetext{
${ }^{19}$ In the figures, we assume the two goods are bundled. But, the same effect can occur even if the goods can be purchased as a bundle or individually as long as some households purchase the goods as a bundle (or if Good 2 has higher average revenue than Good 1).

${ }^{20}$ More widespread deployment is theoretically unambiguous. Since the goods can always be sold separately, there can be no diminution in availability.
} 
income households (homes with incomes less than $y^{*}$ ) if it can sell two services than if the network owner were not permitted to offer both services. The extent of this effect of course also depends upon the shape of the demand curves for the services being examined. With regard to bundles involving multichannel video services in particular, an important demand-side factor is also at play: some studies have shown that demand for video is far less tied to household income than broadband Internet access service. ${ }^{21}$

Figure 3 demonstrates this phenomenon. In Figure $3, r_{12}$ is the same as in Figure 2 (that is, $r_{1}=r_{2}$ ). The curve $r_{12 b}$ represents the revenue-income relationship for the broadband/video bundle in situations where the expenditures for Good 2 are not income sensitive (illustrated by the flat line labeled $r_{2 \mathrm{~b}}$ ). In this case, $r_{2 \mathrm{~b}}+r_{1}=r_{12 \mathrm{~b}}$, which is a significantly flatter curve than $r_{12}$ - meaning that expenditures on the bundle of Good 1 and Good 2 are less-responsive to income than in the previous example (line $r_{12}$ ). Observe that if the capital cost of the bundle is less than $2 k$ (that is, if there are supplyside "spillover" effects) then more low-income homes have access with $r_{12 \mathrm{~b}}$ than with $r_{12}$. For example, at cost $k+d$, redlining falls to $y$ "' with revenues $r_{12 \mathrm{~b}}$, versus $y^{\prime}$ with revenues $r_{12}$. Thus, including a service with relatively low income responsiveness in the bundle will lead to higher deployment to low-income households.

\footnotetext{
${ }^{21}$ Kieschnick and McCullough, "Why Do People Not Subscribe to Cable Television," supra note 7, at 9 ("We find little evidence to support the argument that many of the people who do not subscribe to cable television services do so because they are unable to afford these services. We find that while there is a positive relationship between household income and household expenditures on cable television, this positive relationship is fairly small and largely reflects the purchase of additional cable services, and not the initial decision to subscribe to cable."). The General Accountability Office ("GAO") estimates a negative income elasticity for cable service. See U.S. Government Accountability Office, Direct Broadcast Satellite Subscribership Has Grown Rapidly, but Varies across Different Types of Markets, report prepared for the Subcommittee on Antitrust, Competition Policy and Consumer Rights of the Senate Committee on the Judiciary, 109th Cong., 1st sess., 2005, GAO-05-257 (hereinafter GAO STUDY), 35, table 3 (reporting a statistically significant income elasticity for cable service of -0.3974).
} 


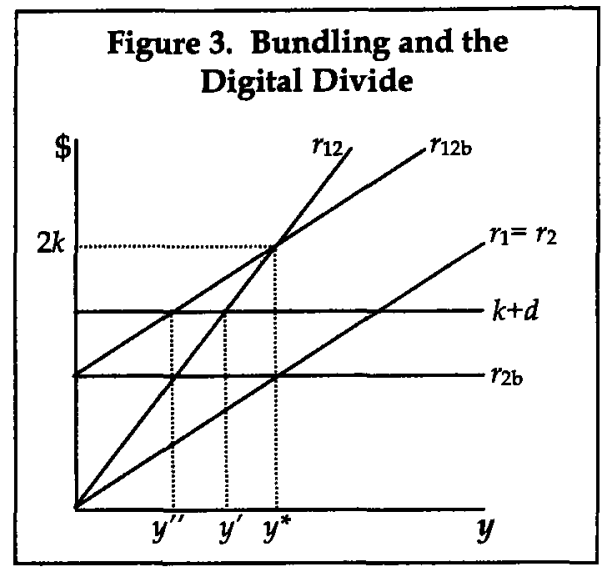

These examples show that, as a matter of theory, broadband Internet access services will become more widely available to lowincome households when service providers gain the ability to sell additional products that utilize the same fiber-optic network. This model also shows that including multichannel video programming service in a particular bundle can play a significant "balancing" role, because consumption of multichannel video is less sensitive to household income than is the consumption of broadband Internet access. The ability to sell video services over a multi-service broadband network increases the revenue potential from low-income households substantially. Moreover, this effect on the economics of broadband network deployment in low-income areas is greater than the impact in high-income areas. As a result, easing restrictions on the sale of video services over a broadband network will stimulate relatively more broadband network deployment in lower-income areas. Stated simply, bundling video with broadband service has a rather pleasant impact on any "digital divide" - while video may be a significant reason why a firm may build a fiber network to lowerincome neighborhoods, citizens in those neighborhoods will also gain access to broadband Internet access services over that same network.

The converse is, of course, sadly true. If a firm is effectively denied or delayed in the ability to sell video services over a broadband network (through regulatory barriers like franchising or weak program access rules), then it will have less incentive to build that broadband network in less-affluent areas. Quite frankly, video revenues are vital to the prospect that firms will rapidly deploy new, fiber-based networks in poor and low-income neighborhoods in significant quantities as required by the nation's goal of universal access by 2007 . 


\section{SIMULATION}

The effect described above can be further illustrated through a computer simulation. Using publicly available data published by the U.S. Census Bureau and a forward-looking cost model of telecommunications plant (the HAI 5.0 cost model), we can evaluate the relationship between services bundling, subscriber income, and service availability. ${ }^{22}$ While the simulation could be performed on any state (or multiple states), our focus for this analysis is the State of Texas. ${ }^{23}$ We initially chose Texas because of its size and geographic and income diversity. This choice was somewhat fortuitous since while conducting our research the Texas Legislature passed a law that makes it significantly easier for new entrants to provide video programming services in that state. ${ }^{24}$ The new Texas law ends the local franchise process and provides a simple and streamlined statewide video provider authorization process. ${ }^{25}$ Moreover, the law does not impose a "build-out" requirement on new video programming entrants in Texas. ${ }^{26}$ "Build-out" rules can significantly increase the costs of a new video entrant and therefore make video entry substantially less likely. ${ }^{27}$

Our simulation is designed to examine the relative relationship between video service availability and the construction of fiber-rich

\footnotetext{
${ }^{22}$ We use a telecommunications cost model where the network uses copper loops, rather than a true fiber-to-the-home model because the latter is not available. Limiting the cost information from the model to loop plant should only provide acceptable estimates of relative costs across markets. One benefit of using the cost model is that the cost estimates are affected by factors that actually drive cost in particular areas (including the design of feeder and distribution plants and geographic characteristics). We believe this to be a substantial improvement over estimating costs based on a single factor such as population density.
}

${ }^{23}$ We consider only the SBC region; it alone provides nearly 15,000 Census Blocks for analysis, which is more than adequate for our purposes.

${ }^{24}$ See Act Relating to Furthering Competition in the Communications Industry, supra note 8.

${ }^{25} I d$.

${ }^{26}$ In doing so, the law brings the Texas multichannel video industry in line with existing federal policy that prohibits "build-out" requirements for new entrants into the local telephone industry. See In the Matter of The Public Utility Commission of Texas, CC Policy Docket Nos. 96-13, 96-14, 96-16, 96-19, Memorandum Opinion and Order, FCC No. 97-346 (rel. Oct. 1, 1997).

${ }^{27}$ See Ford, Koutsky and Spiwak, "The Economics of Build-Out Rules in Cable Television," supra note 6. 
(fiber-to-the-home), multi-service broadband networks. As a result, it makes a number of simplifying assumptions and should not be used to argue or assert that any particular level of build-out or penetration by any firm is achievable or profitable in any time frame. The simulation models include simultaneous entry by two firms that construct advanced communications networks capable of delivering (at least) three services (broadband, digital telephony, and multichannel video). For simplicity, we assume that the two networks enter at the same time and are symmetric (i.e., serving exactly the same areas and dividing the market evenly). Our simulation does not formally model synergies or scope economies available to existing firms deploying new networks, but that does not mean such synergies cannot be inferred (i.e., the effect would be lower costs). Since synergies lower cost, the presence of such synergies would result in more deployment.

We make a number of other simplifying assumptions such as ignoring market growth and assuming instant subscription. We focus on residential customers only. Since we are attempting to examine the extent to which network construction would occur "naturally" without any external regulation, we assume that there are no build-out requirements on either entrant. Demographic data used for the model is from the Census Block Data for the State of Texas, which allows us to simulate income-sensitive revenues. ${ }^{28}$ Finally, we use 1990 Census data because that data aligns with the network cost model that we use, HAI Model 5.0a, which has been employed in various forms by many state public utility commissions in setting rates.

Because of these simplifying assumptions, we do not (indeed, we cannot) project any particular level of availability or penetration in today's environment. Our simulation is simply that - a simulation. One should not infer from this simulation or the tables that follow that a particular penetration rate will be realized, as a number of other factors are at work. Importantly, in today's environment, the vast majority of households receive multichannel video from the incumbent cable company, and many of those incumbent cable companies have vertical programming relationships with the most-popular cable programming networks. Our simulation does not attempt to model the challenges that this situation presents for a new, fiber-based entrant. Moreover, it is not the purpose of this study to show that a "digital divide" is either present currently or eliminated by any particular set of policies.

\footnotetext{
${ }^{28}$ The simulation evaluates Census Blocks in Texas using the 1990 STF3 data. From the STF3 files, we extract households, white households, poverty households, and median income.
} 
That said, our analysis does show that - without much question - $a$ new entrant will deploy broadband Internet access services more widely in low-income neighborhoods if that entrant can freely bundle multichannel video and voice services with broadband Internet service. As illustrated in the previous section, this result is undeniable. This simulation shows that this effect is also significant.

In the following sections, we outline our benchmark case and present the results of the simulation. Appendix A contains sensitivity analysis on many of the inputs.

\section{A. SuPPly SIDE}

The purpose of the simulation is to evaluate the role of bundling multiple services on household access to advanced communications services, with a focus on access differentials by income. We begin by specifying the supply-side of the simulation. At present, there are no highly-disaggregated cost studies of advanced communications networks. We do have, however, forward-looking cost estimates for traditional, copper-based telephone networks and these models provide estimates down to the Census Block level. ${ }^{29}$ While the level of cost for such networks may not be appropriate for a fiber-rich network, such models likely render acceptable approximations of relative costs across geographic areas. ${ }^{30}$ If so, then we can scale the level of cost from these models to match better the advanced communications network.

Say, for example, we know that $k^{F}$ is the true mean cost of the fiber-optic network, but we do not have the distribution of $k^{F}$ across Census Block Groups (the $k_{i}^{F}$ for all $i$ blocks). We do have disaggregated estimates of costs from a forward-looking cost model for a copper-based network $\left(k_{i}^{C}\right)$ with mean cost $k^{C}$. Assuming that the relative cost across Block Groups is the same for both $k^{F}$ and $k^{C}$, if we then scale the cost estimates $k_{i}^{C}$ by the ratio $k^{F} / k^{C}$, then we have legitimate disaggregated cost estimates $k_{i}^{F}$. This approach is employed her. $^{31}$

29 For this study we use the Census Block Group estimates of loop costs from the HAI Model 5.0a.

${ }^{30}$ We use loop costs to proxy relative cost differentials.

${ }^{31}$ While this method is not perfect, it is likely to produce sufficiently good approximations of the cost distribution for the purposes of this simulation. Again, we are trying to illustrate the importance of adding video to the suite of services offered by an advanced communications network, not attempting to provide accurate forecasts of terminal penetration rates. 
We divide capital costs into two major categories. First, we assume the average cost to pass a home $\left(k^{p s s}\right)$ is $\$ 600$, and these costs vary across Census Blocks according to forward-looking cost estimates. For Texas, these costs range from $\$ 61$ to over $\$ 32,000$, depending on population density and other relevant characteristics. In addition, we assume that each house connected to the network costs the firm an additional $\$ 1000$ in labor and materials. ${ }^{32}$ For other services, we assume telephone investment is $\$ 100$ per household, and that the incremental investment to add video to bundle is $\$ 200 \mathrm{per}$ household (from above, these costs are indicated by the variable $d$ ).$^{33}$ For our simulation, the per-home incremental capital cost for broadband service $(k)$ averages $\$ 1600$ by design, $\$ 1800$ for broadband and video, $\$ 1700$ for broadband and telephone, and $\$ 1900$ for all three services. We account for operating costs using margin assumptions as detailed in the next section. A sensitivity analysis of the cost assumptions is provided in Appendix A.

\section{B. DEMAND SIDE}

The revenue-income relationships for our three goods (broadband, voice, and multichannel video) are from published information. Expected revenue per household is computed as $p \cdot e \cdot f$, where $p$ is the probability of purchase (the penetration rate in the block), $e$ is annual expenditures, and $f$ is a present value factor. Both $p$ and $e$ can be functions of income, and $f$ is the discount factor for 15 years at a rate of $10 \%$ (so $f=7.61)$.

For broadband, the relevant demand-side relationships are

\footnotetext{
${ }^{32}$ Using this approach, we derive an average cost of connecting a home to a new fiber-optic network of approximately $\$ 1600$. This average cost figure is consistent with recent studies on the cost of fiber networks including current deployments of fiber-to-the-home. See, e.g.,Render, Vanderslice, \& Associates, LLC, Fiber-To-The-Home, The Third Network, FTTP/FTTH 2004/2005 (Tulsa, OK: 2004); IGI Group, FTTP: Going Strong for 2005 (Brighton, MA: 2005); Carol Mattey, Deloitte \& Touche LLP, "Are Multiple Broadband Infrastructures Sustainable: Key Characteristics of Competing Broadband Platforms" (paper presented at the Columbia Institute for Tele-Information, New York, June 23, 2005); Anupam Banerjee and Marvin Sirbu, "Towards Technologically and Competitively Neutral Fiber to the Home (FTTH) Infrastructure," (working paper, Carnegie Mellon University, Pittsburgh, PA, 2003), http://itc.mit.edu/itel/docs/2003/banerjee sirbu.pdf; Ken Poultin, "The Palo Alto Fiber to the Home Trial: A Work in Progress" (paper presented at the CANARIE's 5th Annual Advanced Networks Workshop, Toronto, ON, November 1999).

${ }^{33}$ See, e.g., Gerry Blackwell, "IPTV: The Big Picture," ISP-Planet, April 15, 2005, http://www.isp-planet.com/research/2005/iptv.html; see also Mattey, "Are Multiple Broadband Infrastructures Sustainable," supra note 32.
} 


$$
\begin{gathered}
p_{b}=(-1.548+0.2024 \cdot \ln y) / 2 \\
e_{b}=(240+0.0033 y) \cdot 0.5 \\
f=7.61 \\
r_{b}=p_{b} \cdot e_{b} \cdot f
\end{gathered}
$$

where both $p_{b}$ and $e_{b}$ are functions of income $(y)$. For the calculation of $p_{b}$, the numerator is aggregate penetration, so we divide by two to reflect the entry of two firms. ${ }^{34}$ Expenditures average $\$ 20$ at the lowest income level rising linearly to an average of $\$ 60$ at the highest income level. ${ }^{35}$ The profit margin (or contribution to fixed costs) is set at $50 \%$ of gross household expenditures, explaining the 0.5 scalar in the $e_{b}$ calculation.

For multichannel video, the demand-side relationships are

$$
\begin{gathered}
p_{v}=0.70 / 2 \\
e_{v}=(-2253.71+314.869 \cdot \ln y) \cdot 0.5 \\
f=7.61 \\
r_{v}=p_{v} \cdot e_{v} \cdot f,
\end{gathered}
$$

where, only $e_{v}$ is a function of income. Econometric studies consistently show a weak relationship (if any) between income and basic cable demand, and we incorporate this finding in our simulation. $^{36}$ Again, we have symmetric duopoly, so the assumed aggregate penetration of $70 \%$, which two firms evenly share, is divided by $2 .^{37}$ Some surveys indicate that expenditures on multichannel video, however, do typically rise with income (but others find no relationship). ${ }^{38}$ To be conservative, we specify the expenditure

\footnotetext{
34 The function for $p_{b}$ is from an informal "best fit" analysis of penetration/income data presented in the NTIA NATION ONLINE REPORT, supra note 4, at table 1. We use "all Internet use" for the penetration rate, explaining the $\$ 20$ monthly revenue for the lowest income groups.

${ }^{35}$ Broadband providers today offer bandwidth options for users. See also Mattey, "Are Multiple Broadband Infrastructures Sustainable," supra note 32 (listing ancillary services for broadband connections).

${ }^{36}$ See Kieschnick and McCullough, "Why Do People Not Subscribe to Cable Television," supra note 7; see also GAO STUDY, supra note 21.

${ }^{37}$ Our approximation of aggregate penetration of $70 \%$ is based on current data from the National Cable Telecommunications Association website which claims that the average household penetration of cable systems is $66.8 \%$. National Cable Telecommunications Web Site, http://www.ncta.com/Docs/PageContent.cfm?pageID $=86$.

${ }^{38}$ Kieschnick and McCullough, "Why Do People Not Subscribe to Cable Television," supra note 7. A recent survey by the Pew Internet \& American Life Project indicates that minority households spend more on multichannel video than white households. Since, on average, white incomes are higher than minority incomes, this finding suggests that low-income households may actually spend more on multichannel video than high-income households.
} 
level $e_{v}$ to be a function of income. ${ }^{39}$ The profit margin (or contribution to fixed costs) is $50 \%$ of gross household expenditures, explaining the 0.5 scalar in the $e_{\nu}$ calculation.

For telecommunications service, we assume that average monthly revenues are $\$ 20$ per household, and that $80 \%$ of homes that buy either broadband or video service also purchase telephone service in a bundle. ${ }^{41}$ Income has no effect, which is plausible with a low-priced $(\$ 20)$, unlimited calling package. The profit margin on the service is $30 \%$.

Thus, our assumptions are conservative in relation to the effect of video on deployment. See John B. Horrigan, Consumption of Information Goods and Services in the United States (Washington, D.C.: Pew Internet \& American Life Project, 2003), www.pewinternet.org/report_display.asp? $1=103$.

${ }^{39}$ The expenditure function $e_{\nu}$ is an informal "best fit" least squares estimation using data from Kieschnick and McCullough, "Why Do People Not Subscribe to Cable Television," supra note 7 , which we scale so that the simple average expenditure is $\$ 80$ per month. We use only income groups with an upper income bound (a use that is bound in the analysis). The mean of $\$ 80$ matches reported average revenue per subscriber in Horrigan, Consumption of Information Goods and Services in the United States, supra note 38. Statistics on the NCTA website indicate a mean of $\$ 95$ per cable subscriber, adjusting out revenues from broadband and telephone services (assuming $\$ 50$ per unit). Cablevision, Inc., reports average revenue per video subscriber of \$87.17. Cablevision Systems Corporation, "SEC Form 10-K" (March 16, 2005): 4, www.secinfo.com/dVut2.z6wd.htm. This mean includes an adjustment for advertising revenue. NCTA reports advertising revenue is about $25 \%$ of industry revenue. The household-weighted average revenue per subscriber in the simulation is $\$ 74$.

${ }^{40}$ Publicly-traded cable operators report gross profits and EBITDA margins in the $40-65 \%$ range.

${ }^{41}$ Cable systems currently offer digital telephone service for about $\$ 40$, and reputable VoIP operators offer a full suite of digital telephone services for about $\$ 25$ to $\$ 35$ per month. See, e.g., Vonage Web site, www.vonage.com and AT\&T Web site, www.att.com. We assume $80 \%$ of subscribers to voice service purchase it from the wireline duopolists in our simulation, leaving the remainder of the voice market to wireless and other carriers (such as VoIP retailers). See, e.g., Sun Microsystems, Telcos Stake Their Claim in the VoIP Market, November 2005, http://www.sun.com/solutions/documents/articles/te_voip_aa.xml?facet=-1 ("weople will tend to buy VoIP service from their broadband provider, it's just a logical progression"'). 


\begin{tabular}{cccccc}
\hline \multicolumn{5}{c}{ Table 1. Descriptive Statistics } \\
(1990 Census Data) \\
\hline $\begin{array}{c}\text { Block Groups by } \\
\begin{array}{c}\text { Median Income } \\
\text { Range }\end{array}\end{array}$ & Homes & $\begin{array}{c}\text { Poverty } \\
\text { Homes }\end{array}$ & $\begin{array}{c}\text { Minority } \\
\text { Homes }\end{array}$ & $k^{\text {pass }}$ & $\begin{array}{c}\text { Median } \\
\text { Income }\end{array}$ \\
\hline$y<20,000$ & $1,155,258$ & 398,950 & 439,657 & 628 & 14,772 \\
$20,000<y<30,000$ & $1,586,374$ & 230,077 & 355,874 & 672 & 24,679 \\
$30,000<y<40,000$ & $1,086,930$ & 81,544 & 164,243 & 584 & 34,352 \\
$40,000<y<50,000$ & 626,473 & 25,585 & 77,614 & 512 & 44,095 \\
$50,000<y<60,000$ & 284,354 & 7,715 & 22,053 & 483 & 54,012 \\
$60,000<y<70,000$ & 153,034 & 3,601 & 9,572 & 483 & 64,025 \\
$70,000<y<80,000$ & 79,172 & 1,520 & 3,864 & 449 & 74,775 \\
$80,000<y<90,000$ & 33,438 & 480 & 1,534 & 463 & 83,600 \\
$90,000<y<100,000$ & 14,976 & 368 & 458 & 457 & 93,633 \\
$100,000<y<125,000$ & 16,444 & 234 & 573 & 428 & 108,583 \\
$125,000<y<150,000$ & 7,808 & 107 & 180 & 428 & 134,951 \\
$y>150,000$ & 6,251 & 183 & 148 & 435 & 150,001 \\
\hline
\end{tabular}

In Table 1 , we present some descriptive statistics jincluding $k^{\text {pass }}$ estimates by income group. The table shows that $k^{p d s}$ is inversely related to income ( $\rho=-0.84$, based on the table values); lower income households are generally located in higher cost areas. ${ }^{42}$ Thus, to some extent, higher costs and not simply lower revenues may explain reduced access to the network in low-income areas. ${ }^{43}$

\section{Results}

Whether or not advanced communications are available to a particular household (or, more appropriately for the simulation, a group of homes in a Census Block) depends on whether the total revenue from homes in the Census Block exceeds the total investment required to serve the Block. On a per-household basis, this implies

\footnotetext{
${ }^{42}$ This high correlation coefficient is in part due to the aggregation into groups. For the individual Census Blocks, there is virtually no linear correlation between income and cost ( $\rho$ $=-0.064$ ), but there may be a non-linear relationship (thus causing the correlation in aggregate data).

${ }^{43}$ This correlation is state-specific and may be different in various states. For example, in many New England states, the correlation is reversed, with poorer homes being located in the more densely populated urban centers.
} 
that a Census Block has access if the average expected revenues exceed the average expected investment (i.e., $r \geq k$ from Section II).

For the benchmark case, the results of the simulation are in Table 2, where we present the results as the percent of households passed by income group for four service offerings: (a) broadband service alone; (b) broadband and telephone service; (c) broadband and video service; and (d) all three services. All results are, of course, conditional on our benchmark assumptions. Appendix A contains a sensitivity analysis of key assumptions.

Table 2 shows a great deal of variability in service availability depending on the components of the service offering. Under our benchmark assumptions with broadband only, the two networks serve very few homes, and the networks pass no homes in areas with median incomes of less than $\$ 50,000$. Obviously, the "broadband only" option leads to a sizeable "digital divide." Even at higher income levels, network coverage is limited for the broadband-only option.

As more services enter the firm's product mix, however, the role of income as a determinant of availability diminishes. If telephone service is bundled with broadband, then availability rises sharply across many income groups. Yet, a substantial "digital" divide remains. No home in a Census Block with a median income of less than $\$ 40,000$ would have access to the network; only about half of the homes in blocks with median incomes in the $\$ 70,000$ to $\$ 80,000$ range would have access.

The most sizeable impact on network coverage happens when the network provider adds video services to its product mix. An offering of video and broadband services shrinks the potential for a "digital divide" considerably. In our simulation, $84 \%$ of the lowest-income Census Blocks have access to the multi-service broadband network, and neighborhoods with median incomes of more than $\$ 40,000$ have near ubiquitous access ( $98 \%$ or more).

A bundle of all three services - voice, data, and video - does even more to eliminate the potential for a "digital divide." Homes in the lowest income group have an $88 \%$ access rate, and virtually every Census Block with a median income of $\$ 40,000$ or more has access. The difference in availability between the three-service bundle and a "broadband only" offering is staggering. With a "triple play," all income groups have very good coverage, and low-income households have substantially more access than they would have if video services were not offered. The simulation illustrates clearly the importance and value of bundling video and other services as an antidote for the "digital divide." 
Table 2. Percent of Homes Passed

(a) (b) (c)

Homes Passed Homes Passed Homes Passed Homes Passed

Block Groups by

Median Income Range
(\%):

Broadband

Only
(\%):

Broadband +

Telephone
(\%):

Broadband + Video
$(\%)$ :

Broadband +

Telephone + Video

\begin{tabular}{ccccc}
\hline$y<20,000$ & - & - & 0.84 & 0.88 \\
$20,000<y<30,000$ & - & - & 0.88 & 0.90 \\
$30,000<y<40,000$ & - & & 0.93 & 0.95 \\
$40,000<y<50,000$ & - & 0.04 & 0.98 & 0.99 \\
$50,000<y<60,000$ & 0.01 & 0.09 & 1.00 & 1.00 \\
$60,000<y<70,000$ & 0.02 & 0.20 & 1.00 & 1.00 \\
$70,000<y<80,000$ & 0.09 & 0.54 & 1.00 & 1.00 \\
$80,000<y<90,000$ & 0.14 & 0.76 & 1.00 & 1.00 \\
$90,000<y$ & & & & 1.00 \\
$<100,000$ & 0.34 & 0.92 & 1.00 & \\
$100,000<y$ & & & & 1.00 \\
$<125,000$ & 0.83 & 1.00 & 1.00 & 1.00 \\
$125,000<y$ & & & & 1.00 \\
$<150,000$ & 0.97 & 0.97 & 1.00 & \\
$y>150,000$ & 1.00 & 1.00 & & 1.00 \\
\hline
\end{tabular}

A review of the detailed simulation results indicates that a lack of access to the network when video is provided is driven more by costs than income (the latter being the sole driver of revenues). The average annual expected net revenues for homes passed versus homes not passed is only $7 \%$ larger ( $\$ 265$ versus $\$ 247){ }^{44}$ In contrast, the cost difference between the groups is enormous. Between the two groups, the average $k$ is $\$ 857$ in served areas whereas the average $k$ in areas not served is $\$ 2685$ (a $213 \%$ difference). ${ }^{45}$ Obviously, cost - and not income - is the primary driver of a lack of access in the simulation.

Another interesting statistic from the simulation is the recovery speed of the upfront investment. If the firm is able to offer all three services over its network, then the firm recoups its upfront investment in about one-third of the time that it would take to recoup from a "broadband-

\footnotetext{
${ }^{44}$ The average is computed as a household weighted average.

${ }^{45}$ These cost figures are average capital costs per home, so the connection and incremental service costs are weighted by the expected penetration.
} 
only" build. ${ }^{46}$ Accelerated cost recovery improves the business case for building a broadband network and substantially reduces the risk of the endeavor.

The increased deployment due to the firm expanding its product mix to include video is particularly significant for low-income and minority households. Figure 4 summarizes the availability of service for households with income below the poverty line and minority homes. "Digital divide" studies often report access statistics based on these demographic traits. If multichannel video services cannot be sold over the broadband network, then our simulation shows the potential for a significant "digital divide," because only a small percentage (less than 1\%) of poor and minority homes gain access to the advanced communications network. Even adding telephone service to the product mix does not improve penetration for these households. Adding video to the product mix, however, makes for a dramatic change in the availability of service to poverty and minority homes. Video service takes on the role of a "silver bullet" - i.e., in our simulation, when the network firm can bundle video, the percentage of poverty and minority homes with access to the network rises from nearly zero to about $90 \%$. The impact of video availability on whether poor households have access to broadband services is considerable and should not be ignored by policymakers.

\footnotetext{
${ }^{46}$ We note, however, that our simulation shows that in many areas, it may still take several years for the entrant to recover the cost of the network. ${ }^{47}$ These figures are based on the relevant household count from Table 1 and the penetration
rates from Table 2 .
} 


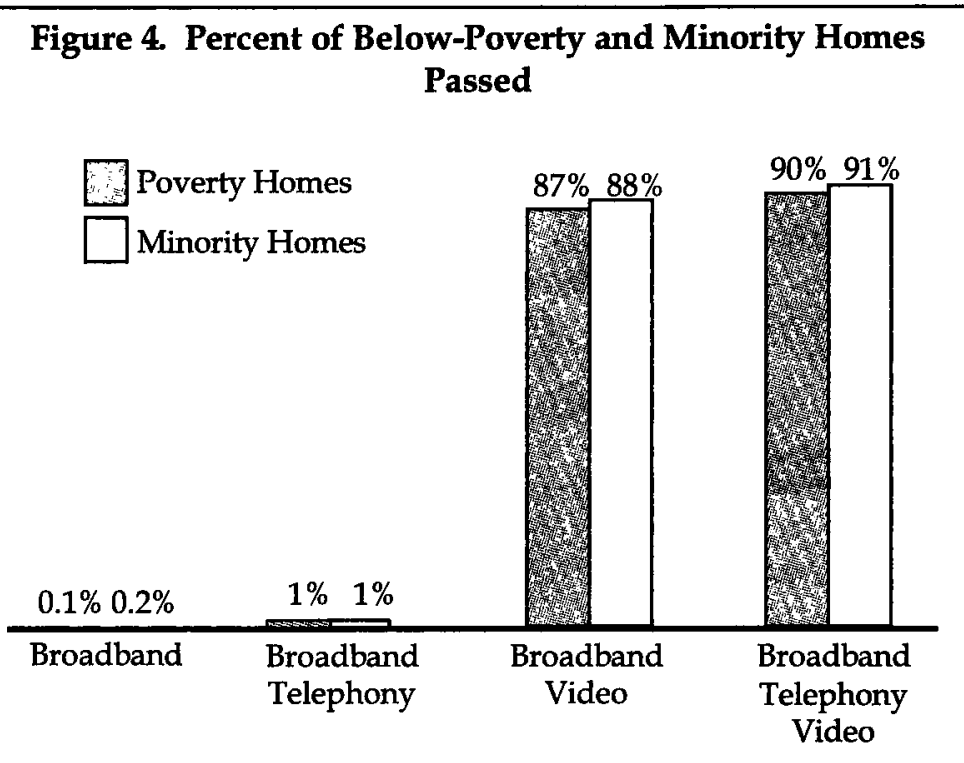

Reviewing the results summarized in Table 2 and Figure 4, the simulation clearly illustrates the point that offering video with broadband service will expand availability across income groups. While we cannot claim a high degree of accuracy on the reported terminal penetration rates from the simulation, the expansion effect predicted by the simulation is substantial and undeniable. These results are unsurprising given that video services generate expected revenues that, on average, are much larger than the expected revenues from broadband services.

Unlike mandatory build-out requirements, which deter entry, allowing entrants easy access to multichannel video services has no downside. Therefore, a public policy of free entry into video markets seems to be a more logical first step in ensuring the widespread deployment of broadband networks. Further, mandatory build-out requirements may be senseless in the context of statewide, or nationwide, franchise arrangements, or when the entrant is an existing network provider (such as a local phone company). In Texas, for example, there are about 60 local phone companies. ${ }^{48}$ It would be ludicrous to require all 60 carriers to build-out to the entire state, since

\footnotetext{
${ }^{48}$ Federal Communications Commission, FCC Universal Service Monitoring Report, CC Docket No. 98-202, December 2003, at Table 3.23, http://www.fcc.gov/wcb/iatd/monitor.html.
} 
it would not be profitable for the firms to do so. Nor does it make sense to require a region-wide build-out, since some entrants may be entirely new to the market and may not have existing networks in a "region." Additionally, local telephone exchanges and cable television franchise markets are not geographically identical. Thus, a build-out requirement based on existing cable franchise boundaries may raise entry costs by forcing a telephone company entrant to expand well beyond its existing markets and infrastructure (which would rob the system of its spillover). ${ }^{49}$ Entry-promoting policies for video services, alternately, have a powerful effect on broadband network deployment and carry no baggage.

\section{SENSITIVITY ANALYSIS}

These reported results are the consequence of the particular assumptions and algorithms of the simulation. In an effort to illustrate the effects of particular assumptions, we summarize a sensitivity analysis in Appendix A. We do not provide sensitivity analysis for a number of key assumptions, such as simultaneous entry and symmetric firms. Some features of the simulation are too complex to evaluate using sensitivity analysis, and quantifying their effect would require a new, more sophisticated simulation. That said, the driving forces of this simulation and any other reasonable simulation of this issue should produce very similar results in a general sense. Accordingly, any simulation, no matter how simple or complex, should indicate that if a firm can provide more services over a network, then the profit opportunities of the firm are enhanced and, as a consequence, the geographic coverage of the network is expanded.

We also performed the simulation using cost data for the states of New Jersey, Pennsylvania, and Maryland. ${ }^{30}$ Despite the significant variation in density and geography across these states, the results were not materially different from those presented in Table 2 and Figure 4. Adding video to the bundle of services dramatically increased the deployment of the broadband network, and this increase was largest in low-income areas. Therefore, it seems reasonable that our findings are

\footnotetext{
${ }^{49}$ C.f., LLC v. City of Otsego, 664 N.W.2d 390 (Minn. Ct. App. 2003).

${ }^{50}$ The results of these simulations may be found at the Web Site for the Phoenix Center for Advanced Legal and Economic Public Policy Studies, www.phoenix-center.org/: http://www.phoenix-center.org/PolicyBulletin/NewJerseyTestimonyFinal.pdf (New Jersey), http://www.phoenix-center.org/KoutskyPATestimonyFinal.pdf (Pennsylvania), and http://www.phoenix-center.org/pcpp/PCPP23AddendumMaryland.pdf (Maryland).
} 
not state specific, and the results can be extrapolated to any geographic area without significant reservation.

We do not devote much attention to the results of the sensitivity analysis - the results are as expected (and robust). Higher revenues and lower costs increase network deployment, and lower revenues and higher costs reduce network deployment.

\section{CONCLUSION}

Republicans and Democrats alike are nearly unanimous in arguing that all Americans should have access to broadband Internet access services. Policymakers fear that consumers without access to this service will increasingly be "passed by" the Information Age - and that those consumers and their children will lose critical educational, employment, and entertainment opportunities.

In this paper, without disputing the social value of ubiquitous broadband deployment, we show that there is an important linkage between the bundling of video programming services and broadband Internet access services. The right set of policies - i.e., policies that facilitate and promote the ability of broadband networks to provide video directly to consumers - will result in wider deployment of broadband Internet services and, in particular, wider deployment in low-income neighborhoods.

The theory demonstrating this relationship builds upon the key insight: the more potential revenues that the network can generate in a household, the more likely it is the network will be built to that household. As a result, it is readily apparent that video can be the key driver in making deployment profitable, and video capability will in turn make broadband Internet access services over that same network platform more readily available. It follows, therefore, that any policy that makes it difficult or costly for a network firm to sell multichannel video services, through either an onerous local franchising process or lax program access regulations will, without a doubt, result in less deployment of advanced communications services, including broadband Internet access. Further, these hindrances to offering video services are particularly detrimental to deployment in low-income areas.

We reiterate that because we use a number of simplifying assumptions in our simulation, our simulation results should not be used to assert that a certain level of penetration is achievable within any particular time period in any particular place. The simulation is intended, primarily, to show the relative rather than the absolute levels of network deployment with and without video services in the bundle. 
In that regard, the simulation analysis reveals that video may be the "silver bullet" for making broadband networks more broadly available across households of all income levels.

APPENDIX A: SENSITIVITY ANALYSIS

A sensitivity analysis of core simulation assumptions is summarized in the tables below. The labels of the columns match that of Table 2. All simulations assume that all other factors remain constant. 


\begin{tabular}{|c|c|c|c|c|c|c|c|c|}
\hline \multicolumn{9}{|c|}{ Percent of Homes Passed } \\
\hline & \multicolumn{4}{|c|}{$k^{\text {pass }}=700$} & \multicolumn{4}{|c|}{$k^{\text {pass }}=500$} \\
\hline $\begin{array}{l}\text { Income } \\
\text { Range }\end{array}$ & (a) & (b) & (c) & (d) & (a) & (b) & (c) & (d) \\
\hline$y<20 \mathrm{k}$ & & & 0.80 & 0.85 & - & - & 0.88 & 0.91 \\
\hline $20 \mathrm{k}<y<30 \mathrm{k}$ & - & - & 0.86 & 0.88 & - & 0.01 & 0.91 & 0.92 \\
\hline $30 \mathrm{k}<y<40 \mathrm{k}$ & & & 0.91 & 0.92 & - & 0.03 & 0.96 & 0.96 \\
\hline $40 \mathrm{k}<y<50 \mathrm{k}$ & & 0.01 & 0.97 & 0.98 & - & 0.10 & 0.99 & 0.99 \\
\hline $50 \mathrm{k}<y<60 \mathrm{k}$ & - & 0.04 & 0.99 & 0.99 & 0.03 & 0.20 & 1.00 & 1.00 \\
\hline $60 \mathrm{k}<y<70 \mathrm{k}$ & & 0.07 & 1.00 & 1.00 & 0.05 & 0.52 & 1.00 & 1.00 \\
\hline $70 \mathrm{k}<y<80 \mathrm{k}$ & 0.05 & 0.21 & 1.00 & 1.00 & 0.21 & 0.79 & 1.00 & 1.00 \\
\hline $80 \mathrm{k}<y<90 \mathrm{k}$ & 0.03 & 0.37 & 1.00 & 1.00 & 0.46 & 0.92 & 1.00 & 1.00 \\
\hline $90 \mathrm{k}<y<100 \mathrm{k}$ & 0.20 & 0.55 & 1.00 & 1.00 & 0.68 & 0.92 & 1.00 & 1.00 \\
\hline $100 \mathrm{k}<y<125 \mathrm{k}$ & 0.54 & 0.83 & 1.00 & 1.00 & 0.93 & 1.00 & 1.00 & 1.00 \\
\hline $125 \mathrm{k}<y<150 \mathrm{k}$ & 0.94 & 0.97 & 1.00 & 1.00 & 0.97 & 1.00 & 1.00 & 1.00 \\
\hline \multirow[t]{2}{*}{$y>150 \mathrm{k}$} & 0.91 & 1.00 & 1.00 & 1.00 & 1.00 & 1.00 & 1.00 & 1.00 \\
\hline & \multicolumn{4}{|c|}{$k^{\text {connect }}=1200$} & \multicolumn{4}{|c|}{$k^{\text {connect }}=800$} \\
\hline $\begin{array}{c}\text { Income } \\
\text { Range }\end{array}$ & (a) & (b) & (c) & (d) & (a) & (b) & (c) & (d) \\
\hline $\mathrm{y}<20 \mathrm{k}$ & & & 0.81 & 0.87 & & - & 0.87 & 0.90 \\
\hline $20 \mathrm{k}<\mathrm{y}<30 \mathrm{k}$ & & & 0.88 & 0.89 & & 0.02 & 0.89 & 0.91 \\
\hline $30 \mathrm{k}<\mathrm{y}<40 \mathrm{k}$ & - & & 0.92 & 0.94 & - & 0.05 & 0.94 & 0.95 \\
\hline $40 \mathrm{k}<\mathrm{y}<50 \mathrm{k}$ & & & 0.98 & 0.99 & 0.01 & 0.12 & 0.99 & 0.99 \\
\hline $50 \mathrm{k}<\mathrm{y}<60 \mathrm{k}$ & & 0.03 & 1.00 & 1.00 & 0.04 & 0.21 & 1.00 & 1.00 \\
\hline $60 \mathrm{k}<\mathrm{y}<70 \mathrm{k}$ & & 0.05 & 1.00 & 1.00 & 0.07 & 0.47 & 1.00 & 1.00 \\
\hline $70 \mathrm{k}<\mathrm{y}<80 \mathrm{k}$ & 0.04 & 0.21 & 1.00 & 1.00 & 0.24 & 0.76 & 1.00 & 1.00 \\
\hline $80 \mathrm{k}<\mathrm{y}<90 \mathrm{k}$ & 0.03 & 0.35 & 1.00 & 1.00 & 0.46 & 0.92 & 1.00 & 1.00 \\
\hline $90 \mathrm{k}<\mathrm{y}<100 \mathrm{k}$ & 0.20 & 0.58 & 1.00 & 1.00 & 0.59 & 0.92 & 1.00 & 1.00 \\
\hline $100 \mathrm{k}<\mathrm{y}<125 \mathrm{k}$ & 0.54 & 0.83 & 1.00 & 1.00 & 0.92 & 1.00 & 1.00 & 1.00 \\
\hline $125 \mathrm{k}<\mathrm{y}<150 \mathrm{k}$ & 0.94 & 0.97 & 1.00 & 1.00 & 0.97 & 0.97 & 1.00 & 1.00 \\
\hline$y>150 k$ & 0.91 & 1.00 & 1.00 & 1.00 & 1.00 & 1.00 & 1.00 & 1.00 \\
\hline
\end{tabular}


Percent of Homes Passed

\begin{tabular}{|c|c|c|c|c|c|c|c|c|}
\hline & \multicolumn{4}{|c|}{$p_{b}+10 \%$} & \multicolumn{4}{|c|}{$p_{b}-10 \%$} \\
\hline $\begin{array}{l}\text { Income } \\
\text { Range }\end{array}$ & (a) & (b) & (c) & (d) & (a) & (b) & (c) & (d) \\
\hline $\mathrm{y}<20 \mathrm{k}$ & - & - & 0.85 & 0.89 & & & 0.83 & 0.88 \\
\hline $20 \mathrm{k}<\mathrm{y}<30 \mathrm{k}$ & & 0.01 & 0.89 & 0.90 & - & - & 0.88 & 0.90 \\
\hline $30 \mathrm{k}<\mathrm{y}<40 \mathrm{k}$ & & 0.03 & 0.94 & 0.95 & - & & 0.93 & 0.94 \\
\hline $40 \mathrm{k}<\mathrm{y}<50 \mathrm{k}$ & - & 0.10 & 0.98 & 0.99 & - & 0.01 & 0.98 & 0.99 \\
\hline $50 \mathrm{k}<\mathrm{y}<60 \mathrm{k}$ & 0.03 & 0.17 & 1.00 & 1.00 & & 0.04 & 1.00 & 1.00 \\
\hline $60 \mathrm{k}<\mathrm{y}<70 \mathrm{k}$ & 0.06 & 0.44 & 1.00 & 1.00 & - & 0.06 & 1.00 & 1.00 \\
\hline $70 \mathrm{k}<\mathrm{y}<80 \mathrm{k}$ & 0.21 & 0.76 & 1.00 & 1.00 & 0.04 & 0.21 & 1.00 & 1.00 \\
\hline $80 \mathrm{k}<\mathrm{y}<90 \mathrm{k}$ & 0.46 & 0.92 & 1.00 & 1.00 & 0.03 & 0.35 & 1.00 & 1.00 \\
\hline $90 \mathrm{k}<\mathrm{y}<100 \mathrm{k}$ & 0.63 & 0.92 & 1.00 & 1.00 & 0.20 & 0.55 & 1.00 & 1.00 \\
\hline $100 \mathrm{k}<\mathrm{y}<125 \mathrm{k}$ & 0.93 & 1.00 & 1.00 & 1.00 & 0.54 & 0.83 & 1.00 & 1.00 \\
\hline $125 \mathrm{k}<\mathrm{y}<150 \mathrm{k}$ & 0.97 & 0.97 & 1.00 & 1.00 & 0.94 & 0.97 & 1.00 & 1.00 \\
\hline$y>150 k$ & 1.00 & 1.00 & 1.00 & 1.00 & 0.91 & 1.00 & 1.00 & 1.00 \\
\hline
\end{tabular}

\begin{tabular}{|c|c|c|c|c|c|c|c|c|}
\hline & \multicolumn{4}{|c|}{$p_{v}+10 \%$} & \multicolumn{4}{|c|}{$p_{v}-10 \%$} \\
\hline $\begin{array}{c}\text { Income } \\
\text { Range }\end{array}$ & (a) & (b) & (c) & (d) & (a) & (b) & (c) & (d) \\
\hline$y<20 k$ & - & - & 0.87 & 0.90 & & & 0.80 & 0.86 \\
\hline $20 \mathrm{k}<\mathrm{y}<30 \mathrm{k}$ & & - & 0.90 & 0.91 & & & 0.87 & 0.88 \\
\hline $30 \mathrm{k}<\mathrm{y}<40 \mathrm{k}$ & - & & 0.95 & 0.96 & & - & 0.92 & 0.93 \\
\hline $40 \mathrm{k}<\mathrm{y}<50 \mathrm{k}$ & - & 0.04 & 0.99 & 0.99 & - & 0.04 & 0.98 & 0.98 \\
\hline $50 \mathrm{k}<\mathrm{y}<60 \mathrm{k}$ & 0.01 & 0.09 & 1.00 & 1.00 & 0.01 & 0.09 & 0.99 & 1.00 \\
\hline $60 \mathrm{k}<\mathrm{y}<70 \mathrm{k}$ & 0.02 & 0.20 & 1.00 & 1.00 & 0.02 & 0.20 & 1.00 & 1.00 \\
\hline $70 \mathrm{k}<\mathrm{y}<80 \mathrm{k}$ & 0.09 & 0.54 & 1.00 & 1.00 & 0.09 & 0.54 & 1.00 & 1.00 \\
\hline $80 \mathrm{k}<\mathrm{y}<90 \mathrm{k}$ & 0.14 & 0.76 & 1.00 & 1.00 & 0.14 & 0.76 & 1.00 & 1.00 \\
\hline $90 \mathrm{k}<\mathrm{y}<100 \mathrm{k}$ & 0.34 & 0.92 & 1.00 & 1.00 & 0.34 & 0.92 & 1.00 & 1.00 \\
\hline $100 \mathrm{k}<\mathrm{y}<125 \mathrm{k}$ & 0.83 & 1.00 & 1.00 & 1.00 & 0.83 & 1.00 & 1.00 & 1.00 \\
\hline $125 \mathrm{k}<\mathrm{y}<150 \mathrm{k}$ & 0.97 & 0.97 & 1.00 & 1.00 & 0.97 & 0.97 & 1.00 & 1.00 \\
\hline$y>150 k$ & 1.00 & 1.00 & 1.00 & 1.00 & 1.00 & 1.00 & 1.00 & 1.00 \\
\hline
\end{tabular}




\section{Percent of Homes Passed}

\begin{tabular}{c|cccc|c|cccc}
\hline & \multicolumn{4}{|c|}{ All Revenue $+10 \%$} & & \multicolumn{3}{c}{ All Revenue $-10 \%$} \\
\hline $\begin{array}{c}\text { Income } \\
\text { Range }\end{array}$ & (a) & (b) & (c) & (d) & & (a) & (b) & (c) & (d) \\
\hline $\mathrm{y}<20 \mathrm{k}$ & & & 0.88 & 0.90 & & - & & 0.79 & 0.85 \\
$20 \mathrm{k}<\mathrm{y}<30 \mathrm{k}$ & - & 0.01 & 0.90 & 0.91 & & & & 0.87 & 0.88 \\
$30 \mathrm{k}<\mathrm{y}<40 \mathrm{k}$ & - & 0.04 & 0.95 & 0.96 & & - & & 0.91 & 0.92 \\
$40 \mathrm{k}<\mathrm{y}<50 \mathrm{k}$ & - & 0.12 & 0.99 & 0.99 & & - & - & 0.97 & 0.98 \\
$50 \mathrm{k}<\mathrm{y}<60 \mathrm{k}$ & 0.03 & 0.21 & 1.00 & 1.00 & & & 0.03 & 0.99 & 0.99 \\
$60 \mathrm{k}<\mathrm{y}<70 \mathrm{k}$ & 0.06 & 0.52 & 1.00 & 1.00 & & - & 0.05 & 1.00 & 1.00 \\
$70 \mathrm{k}<\mathrm{y}<80 \mathrm{k}$ & 0.21 & 0.79 & 1.00 & 1.00 & & 0.04 & 0.20 & 1.00 & 1.00 \\
$80 \mathrm{k}<\mathrm{y}<90 \mathrm{k}$ & 0.46 & 0.92 & 1.00 & 1.00 & & 0.03 & 0.32 & 1.00 & 1.00 \\
$90 \mathrm{k}<\mathrm{y}<100 \mathrm{k}$ & 0.63 & 0.92 & 1.00 & 1.00 & & 0.20 & 0.53 & 1.00 & 1.00 \\
$100 \mathrm{k}<\mathrm{y}<125 \mathrm{k}$ & 0.93 & 1.00 & 1.00 & 1.00 & & 0.54 & 0.83 & 1.00 & 1.00 \\
$125 \mathrm{k}<\mathrm{y}<150 \mathrm{k}$ & 0.97 & 0.97 & 1.00 & 1.00 & & 0.94 & 0.97 & 1.00 & 1.00 \\
$\mathrm{y}>150 \mathrm{k}$ & 1.00 & 1.00 & 1.00 & 1.00 & & 0.91 & 1.00 & 1.00 & 1.00 \\
\hline
\end{tabular}

\begin{tabular}{|c|c|c|c|c|c|c|c|c|}
\hline \multirow[b]{2}{*}{$\begin{array}{c}\text { Income } \\
\text { Range }\end{array}$} & \multicolumn{4}{|c|}{ Video Share $=40 \%$} & \multicolumn{4}{|c|}{ Video Share $=60 \%$} \\
\hline & (a) & (b) & (c) & (d) & (a) & (b) & (c) & (d) \\
\hline $\mathrm{y}<20 \mathrm{k}$ & & - & 0.79 & 0.84 & - & & 0.87 & 0.90 \\
\hline $20 \mathrm{k}<\mathrm{y}<30 \mathrm{k}$ & - & & 0.86 & 0.88 & - & - & 0.90 & 0.92 \\
\hline $30 \mathrm{k}<\mathrm{y}<40 \mathrm{k}$ & - & - & 0.91 & 0.92 & & - & 0.95 & 0.96 \\
\hline $40 \mathrm{k}<\mathrm{y}<50 \mathrm{k}$ & - & 0.04 & 0.97 & 0.98 & - & 0.04 & 0.99 & 0.99 \\
\hline $50 \mathrm{k}<\mathrm{y}<60 \mathrm{k}$ & 0.01 & 0.09 & 0.99 & 0.99 & 0.01 & 0.09 & 1.00 & 1.00 \\
\hline $60 \mathrm{k}<\mathrm{y}<70 \mathrm{k}$ & 0.02 & 0.20 & 1.00 & 1.00 & 0.02 & 0.20 & 1.00 & 1.00 \\
\hline $70 \mathrm{k}<\mathrm{y}<80 \mathrm{k}$ & 0.09 & 0.54 & 1.00 & 1.00 & 0.09 & 0.54 & 1.00 & 1.00 \\
\hline $80 \mathrm{k}<\mathrm{y}<90 \mathrm{k}$ & 0.14 & 0.76 & 1.00 & 1.00 & 0.14 & 0.76 & 1.00 & 1.00 \\
\hline $90 \mathrm{k}<\mathrm{y}<100 \mathrm{k}$ & 0.34 & 0.92 & 1.00 & 1.00 & 0.34 & 0.92 & 1.00 & 1.00 \\
\hline $100 \mathrm{k}<\mathrm{y}<125 \mathrm{k}$ & 0.83 & 1.00 & 1.00 & 1.00 & 0.83 & 1.00 & 1.00 & 1.00 \\
\hline $125 \mathrm{k}<\mathrm{y}<150 \mathrm{k}$ & 0.97 & 0.97 & 1.00 & 1.00 & 0.97 & 0.97 & 1.00 & 1.00 \\
\hline$y>150 k$ & 1.00 & 1.00 & 1.00 & 1.00 & 1.00 & 1.00 & 1.00 & 1.00 \\
\hline
\end{tabular}




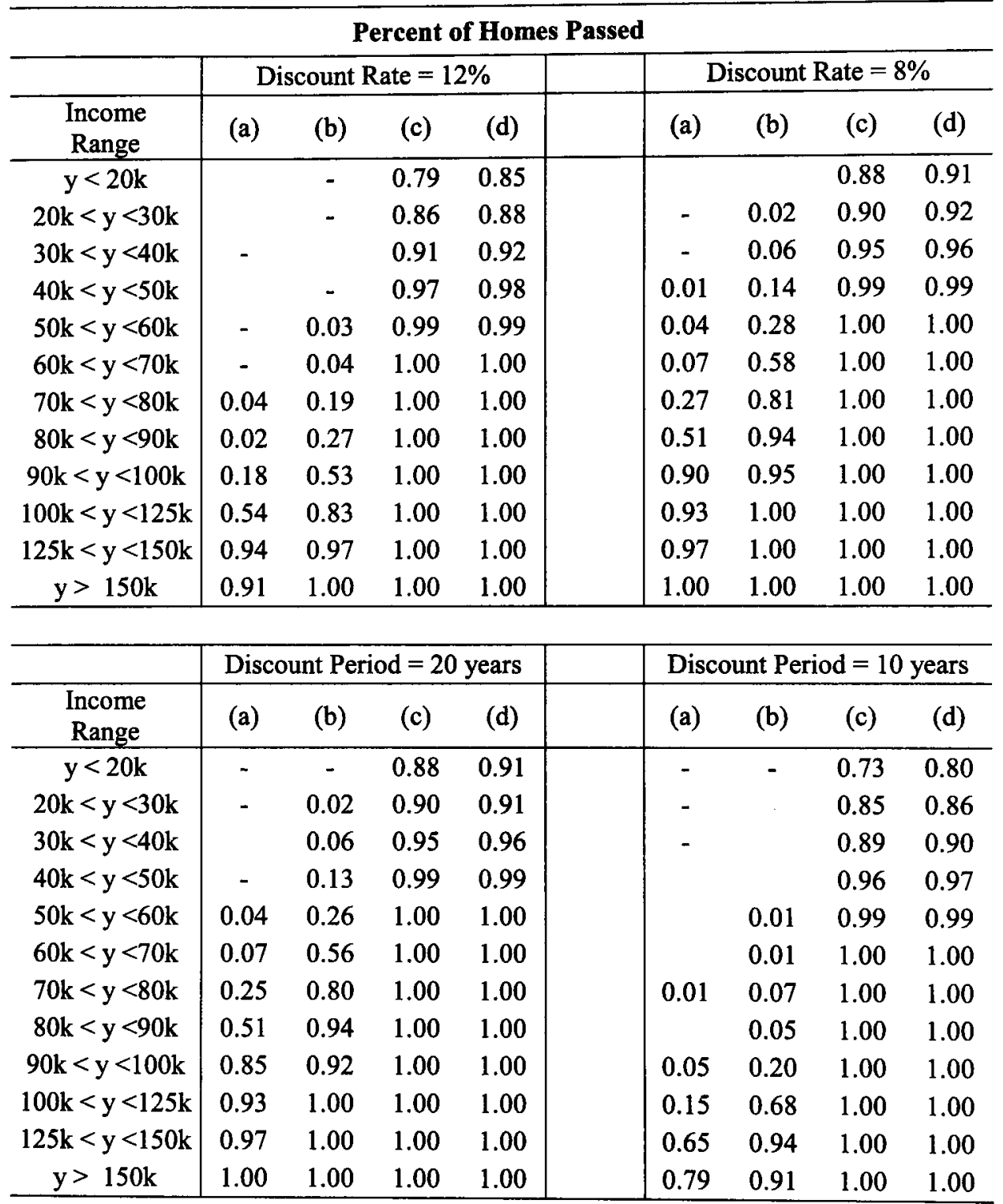


